\section{Trichomonas vaginalis screening and prevention in order to impact the HIV pandemic: Isn't it time we take this infection seriously?}

\author{
Gweneth B. Lazenby \\ Department of Obstetrics and \\ Gynecology, Medical University of South \\ Carolina, Charleston, SC, USA
}

\section{Abstract}

Trichomonas vaginalis (TV) is the second most common sexually transmitted infection (STI) in the world. It is associated with significant morbidity in women: pelvic inflammatory disease (PID), concurrent vaginitis and sexually transmitted infections (STIs), post-operative infection, and pregnancy complications. TV infection has been implicated in HIV acquisition and transmission in men and women. There are multiple mechanisms to explain this association. TV is not routinely screened for in asymptomatic patients; however, infected individuals are most often asymptomatic. Due to the association with the spread of HIV infection, screening should not be limited to symptomatic patients or those seeking treatment for STIs. There are a variety of tests available to detect TV. Treatment of TV has demonstrated lower rates of HIV acquisition in at risk women. In HIV positive men and women, treatment decreases the amount of genital HIV shedding and subsequent infectivity. Initiation of an effective TV screening and treatment program in HIV positive and HIV susceptible populations may limit further transmission of HIV.

Worldwide, more than 33 million people are infected with Human Immunodeficiency Virus (HIV). ${ }^{1}$ Seventy-five percent of cases globally are attributable to heterosexual contact. ${ }^{2,3}$ Risky sexual behaviors are associated with sexually transmitted infections (STIs) and patients reporting a history of or presenting with an STI are at increased risk of HIV acquisition. ${ }^{4-10}$ Trichomonas vaginalis (TV) is the second most common STI in the world, accounting for $30 \%$ of STI cases., ${ }^{2,5,6,11-15}$ Trichomonas has been associated with a 1.5 (1.5-3.0) times increased risk of HIV acquisition and implicated as a cause of increased risk of transmission. ${ }^{15-20}$ Although modest, this increase in risk for both transmission and acquisition of HIV is significant given the large burden of TV infection worldwide.,15 In light of the suspected contribution of TV on the HIV pandemic, active surveillance and treatment of TV may result in a significant reduc- tion in the spread of HIV.

Trichomonas vaginalis is a single-celled protozoan that causes vaginitis in women and urethritis in men. ${ }^{6,11,16}$ Each year, there are approximately 200 million new cases of TV worldwide and 3-5 million in the United States. ${ }^{5,21,22}$ The majority of patients with TV are asymptomatic. $70-100 \%$ of men are asymptomatic versus $30-85 \%$ of women. ${ }^{12-14,19,23,24}$ Symptomatic women may present with any combination of vaginal discharge, odor, vulvar irritation and itching, dysuria, abdominal pain, and dyspareunia..$^{13,14,25}$ Symptomatic men present with urethritis and infrequently prostatitis, epididymitis, and penile discharge. ${ }^{14}$ TV is associated with significant morbidity in women: pelvic inflammatory disease (PID), post-operative infection, cervical dysplasia, and low birth weight infants. ${ }^{13}$ TV is more prevalent in HIV positive women with similar rates of recurrence..$^{21,26,27}$ Multiple investigations have cited an association between TV and HIV transmission and acquisition. ${ }^{3,13,15,16,19,24}$ There are several plausible biologic mechanisms that support this association. . $^{15}$

Proposed mechanisms for increased HIV acquisition in TV infected individuals include: i) prolonged asymptomatic infection may increase the susceptibility to HIV acquisition; ${ }^{13,15,25,28,29}$ ii) TV causes micro-tears in the genital epithelium which may allow entry of HIV into circulation; $;, 5,6,8,13,15,18,26,30$ iii) TV leads to an increased recruitment of inflammatory cells that are more susceptible to HIV; $5,8,9,13$, $16,18,30-32$ and iv) TV inhibits the production of immune cells that are able to bind to and block HIV infection..$^{15}$ A high proportion of patients with TV infections are asymptomatic, and infections may persist from 3-12 months. ${ }^{13,27,33}$ TV is more common in older individuals, which may be a reflection of long-standing asymptomatic carriage. ${ }^{13,25}$ In HIV susceptible patients, this may lead to a prolonged period of increased risk of HIV acquisition. ${ }^{15,28,29}$ Trichomonads adhere to and phagocytose epithelial cells causing punctuate hemorrhages in the epithelial layer of the vagina. ${ }^{34}$ These breaks in the epithelium allow for entry of HIV into host circulation. ${ }^{6,15}$ HIV may also attach to trichomonads and gain access to the basement membrane by hitching a ride to areas where are inflammatory cells have been recruited. ${ }^{2}$ TV elicits a robust immune response resulting in the recruitment of HIV-susceptible inflammatory cells. $2,6,15,16,18,30$ In addition, TV degrades secretory leukocyte protease inhibitors, which normally block HIV attachment to cells. This allows for increased attachment of HIV to susceptible immune cells. ${ }^{15}$

In regards to increased risk of HIV transmission, HIV positive patients infected with TV have higher rates of HIV genital shedding. ${ }^{6,10,11,13,19,21,28,30,32}$ Maternal to child
Correspondence: Gweneth B. Lazenby, MD FACOG, c/o MUSC Department of OBGYN, 96 Jonathan Lucas Street, Suite 634, MSC 619, Charleston, SC 29425

Tel. 843-792-6212 - Fax. 843-792-0533. Email: lazenbgb@musc.edu

Key words: Trichomonas vaginalis, Human Immunodeficiency Virus (HIV), HIV prevention, sexually transmitted infections (STIs)

Acknowledgments: David E. Soper MD, mentor and director of MUSC reproductive infectious diseases fellowship; Roger Newman, MD FACOG, mentor and director of MUSC maternal-fetal medicine fellowship; J. Michael Kilby MD, division director of adult infectious diseases.

Conflict of interest: the authors report no conflicts of interest.

Received for publication: 14 February 2011.

Revision received: 1 April 2011.

Accepted for publication: 4 April 2011.

This work is licensed under a Creative Commons Attribution 3.0 License (by-nc 3.0)

(C) Copyright G.B. Lazenby, 2011

Licensee PAGEPress, Italy

Infectious Disease Reports 2011; 3:e4

doi:10.4081/idr.2011.e4

(MTCT) and sexual HIV transmission are directly related to viral genital shedding. ${ }^{32,35}$ Increased genital HIV shedding is associated with increased infectivity. ${ }^{21}$ Factors associated with increased genital shedding include: low host CD4 cell count, high plasma viral load, cervical inflammation, pregnancy, and STI coinfection. ${ }^{11,30,32,35}$ Male and female patients infected with TV demonstrate increased rates of genital HIV shedding. . $^{15,19,26,28,36}$ This may result from TV inducing TNF- $\alpha$, which increases the rate of HIV replication. ${ }^{2}$ Treatment of TV in HIV positive men and women decreases genital shedding, but the response is delayed over a period of up to 3 weeks following therapy, possibly due to the robust inflammatory response associated with TV infection. ${ }^{10,11}$ By decreasing genital HIV shedding, treatment of TV infection in HIV positive patients may result in decreased infectivity through MTCT or heterosexual contact. ${ }^{32}$

In order to effectively decrease the risk of HIV acquisition and transmission as a result of TV infections, accurate diagnostic techniques must be employed in order to identify and treat infected individuals. The current standard for diagnosis of TV is culture. ${ }^{13}$ In comparison to PCR, culture is $70-80 \%$ sensitive. ${ }^{15,25}$ The viability of the organisms collected for culture has a significant impact on sensitivity. Cultures should be inoculated immediately. If not inoculated within one hour, the viability of TV is 
lost and culture becomes ineffective. ${ }^{15}$ Cultures in men may be inoculated from urine or a urethral swab whereas a vaginal swab is preferable in females. ${ }^{13,14,23,25,28,36,37}$ The disadvantages of culture are required incubation at $37^{\circ} \mathrm{C}$, availability of a microscope, trained personnel to interpret the culture, and results may take up to 5 days. ${ }^{14}$ These limitations are more pronounced in low resource settings. Microscopy, which is limited by low sensitivity in both sexes (60-80\%), is most often used in the United States and worldwide for diagnosis of TV. ${ }^{13,15,19,23}$ Papinicolaou smears have a low sensitivity (57\%) and should not be used for TV screening or diagnosis. ${ }^{15}$ Point of care tests that are available and FDA-approved for the diagnosis of TV include the OSOM Trichomonas Rapid Test (Genzyme Diagnostics, Cambridge, Massachusetts) and the Affirm VP III (Becton Dickenson, San Jose, California). ${ }^{38}$ The Gen-Probe APTIMA Combo2 nucleic acid amplification test for detection of $N$. gonorrhoeae and $C$. trachomatis can be augmented with TV Analyte Specific Reagents (ASR) in order to detect TV. ${ }^{39}$ PCR and point of care tests have increased sensitivity and detection over culture or microscopy, especially in men. ${ }^{12-15,28}$ However, these methods are associated with increased cost and equipment for analysis, which are not available in developing countries or low resource settings in the United States.

Treatment of TV infection is affordable and effective. The preferred therapies for TV are a single $2000 \mathrm{mg}$ dose of metronidazole or tindazole. ${ }^{15,27,38,40}$ Extended therapy using metronidazole $500 \mathrm{mg}$ twice daily for 7 days may be more effective in treating males and HIV positive women. ${ }^{41,42}$ Untreated partners may serve as a reservoir for re-infection of treated patients. ${ }^{19}$ It has been demonstrated that sexual transmission rates of TV are high. 85-100\% of female partners of TV infected men and 45$70 \%$ of men with infected female partners are noted to be concurrently infected. ${ }^{14,43-46}$ Rates of resistance to metronidazole are relatively low (2-5\%) and do not differ based on HIV status. ${ }^{27}$ Ineffectual treatment of both partners due to non-compliance or non-disclosure of infection to partners may explain the observed rates of recurrence, $5-8 \%$ in HIV negative patients versus $30 \%$ in HIV positive patients. ${ }^{15,21,27}$ Due to high rates of recurrent TV infection, the recent Center for Disease Control (CDC) 2010 Sexually Transmitted Diseases Treatment Guidelines now recommend repeat TV testing 3 months following an initial infection. ${ }^{38}$ Tests of cure are not currently recommended following TV treatment; however, due to high rates of recurrence and asymptomatic carriage, especially in HIV infected patients, this may be reasonable to assure effective therapy has been delivered. ${ }^{13}$

Diagnosis and treatment of TV infections in
HIV susceptible patients and HIV positive patients with susceptible partners may have a significant impact on healthcare costs. TV increases a women's risk of HIV acquisition by $1.5-3$ fold. It is estimated that TV is associated with $6 \%$ of the 12,000 newly diagnosed HIV infections in the United States each year. These TV-associated HIV cases account for a lifetime cost of $\$ 167$ million dollars. ${ }^{15,16}$ Given high rates of asymptomatic carriage, a screening approach in at risk men and women is best in order to impact HIV infection rates. ${ }^{13,19,37}$ The CDC recommends annual TV screening in HIV positive women with repeat screening 3 months following infection due to high rates of recurrence. There are no recommendations for TV screening in HIV positive men, most likely due to poor sensitivity in non-PCR diagnostic methods in males..$^{27,38,47}$ Currently, there is no recommendation for screening in other at risk populations. In the United States, African Americans are at significant risk for both TV and HIV infections. ${ }^{24}$ African Americans have 1.5-10x higher rates of TV infection than any other racial or ethnic group and are disproportionately affected by the HIV pandemic. ${ }^{15,24,26}$ Associated risk factors that have been suggested to increase rates in African Americans over other racial groups include: poverty, early initiation of sexual activity, increased number of lifetime sexual partners infected with TV, infrequent condom use, and low level of education. ${ }^{13,15,20,24,48-50}$ Other risk factors for TV infection include: illicit drug use, tobacco use, incarceration, prostitution, vaginal douching, intact foreskin, vaginitis, and concurrent STIs. 3,7,13,14,18,26,30,36,37 Given the identified risk factors and at risk populations, it is in the hands of health care providers to embrace screening and treatment of TV infections.

The evidence supporting increased risk of HIV acquisition and transmission in patients with TV infection is substantial. Risk factors and populations at risk for both infections are well defined. However, complacency and a lack of urgency regarding TV diagnosis and treatment in asymptomatic carriers, particularly males, is commonplace. Even in STI clinic settings where providers are screening for TV, diagnosis is most often made by microscopy, which is inferior to culture and PCR. TV is the second most common STI, diagnostic techniques are available in most settings, and treatment is affordable and effective. Given the high probability of current partner infection and recurrent infections, expedited partner therapy and return visits for tests of cure before the recommended 3 months should be considered. By actively identifying and treating TV, not only is there the potential to impact the spread of HIV infection but also rates of pelvic inflammatory disease, bacterial and viral STI acquisition, post-operative infection, and pregnancy complications. TV screening in at risk populations, especially HIV positive patients, should be embraced by health care providers.

\section{References}

1. Croce F, Piconi S, Atzeni F, et al. HIV/AIDS: epidemic update, new treatment strategies and impact on autoimmunity. Clin Exp Rheumatol 2008;26:S48-52.

2. Guenthner PC, Secor WE, Dezzutti CS. Trichomonas vaginalis-induced epithelial monolayer disruption and human immunodeficiency virus type 1 (HIV-1) replication: implications for the sexual transmission of HIV-1. Infect Immun 2005;73:415560.

3. Laga M, Manoka A, Kivuvu M, et al. Nonulcerative sexually transmitted diseases as risk factors for HIV-1 transmission in women: results from a cohort study. AIDS 1993;7:95-102.

4. Sexton J, Garnett G, Rottingen JA. Metaanalysis and metaregression in interpreting study variability in the impact of sexually transmitted diseases on susceptibility to HIV infection. Sex Transm Dis 2005;32:351-7.

5. Draper D, Donohoe W, Mortimer L, Heine RP. Cysteine proteases of Trichomonas vaginalis degrade secretory leukocyte protease inhibitor. J Infect Dis 1998;178:8159 .

6. Niccolai LM, Kopicko JJ, Kassie A, et al. Incidence and predictors of reinfection with Trichomonas vaginalis in HIV-infected women. Sex Transm Dis 2000;27:284-8.

7. Pepin J, Plummer FA, Brunham RC, et al. The interaction of HIV infection and other sexually transmitted diseases: an opportunity for intervention. AIDS 1989;3:3-9.

8. Mertens TE, Hayes RJ, Smith PG. Epidemiological methods to study the interaction between HIV infection and other sexually transmitted diseases. AIDS 1990;4:57-65.

9. Levine WC, Pope V, Bhoomkar A, et al. Increase in endocervical CD4 lymphocytes among women with nonulcerative sexually transmitted diseases. J Infect Dis 1998;177:167-74.

10. Cohen MS, Hoffman IF, Royce RA, et al. Reduction of concentration of HIV-1 in semen after treatment of urethritis: implications for prevention of sexual transmission of HIV-1. AIDSCAP Malawi Research Group. Lancet 1997;349:1868-73.

11. Kissinger P, Amedee A, Clark RA, et al. Trichomonas vaginalis treatment reduces vaginal HIV-1 shedding. Sex Transm Dis 2009;36:11-6.

12. Van Der Pol B, Williams JA, Orr DP, et al. 
Prevalence, incidence, natural history, and response to treatment of Trichomonas vaginalis infection among adolescent women. J Infect Dis 2005;192:2039-44.

13. Johnston VJ, Mabey DC. Global epidemiology and control of Trichomonas vaginalis. Curr Opin Infect Dis 2008;21:56-64.

14. Sena AC, Miller WC, Hobbs MM, et al. Trichomonas vaginalis infection in male sexual partners: implications for diagnosis, treatment, and prevention. Clin Infect Dis 2007;44:13-22.

15. Shafir SC, Sorvillo FJ, Smith L. Current issues and considerations regarding trichomoniasis and human immunodeficiency virus in African-Americans. Clin Microbiol Rev 2009;22:37-45.

16. Chesson HW, Blandford JM, Pinkerton SD. Estimates of the annual number and cost of new HIV infections among women attributable to trichomoniasis in the United States. Sex Transm Dis 2004;31: 547-51.

17. Rottingen JA, Cameron DW, Garnett GP. A systematic review of the epidemiologic interactions between classic sexually transmitted diseases and HIV: how much really is known? Sex Transm Dis 2001;28: 579-97.

18. McClelland RS, Sangare L, Hassan WM, et al. Infection with Trichomonas vaginalis increases the risk of HIV-1 acquisition. J Infect Dis 2007;195:698-702.

19. Van der Pol B. Trichomonas vaginalis infection: the most prevalent nonviral sexually transmitted infection receives the least public health attention. Clin Infect Dis 2007;44:23-5.

20. Sorvillo F, Smith L, Kerndt P, Ash L. Trichomonas vaginalis, HIV, and AfricanAmericans. Emerg Infect Dis 2001;7:92732.

21. Magnus M, Clark R, Myers L, et al. Trichomonas vaginalis among HIVInfected women: are immune status or protease inhibitor use associated with subsequent T. vaginalis positivity? Sex Transm Dis 2003;30:839-43.

22. Spinillo A, Zara F, Gardella B, et al. The effect of vaginal candidiasis on the shedding of human immunodeficiency virus in cervicovaginal secretions. Am J Obstet Gynecol 2005;192:774-9.

23. Borchardt KA, al-Haraci S, Maida N. Prevalence of Trichomonas vaginalis in a male sexually transmitted disease clinic population by interview, wet mount microscopy, and the InPouch TV test. Genitourin Med 1995;71:405-6.

24. Sutton M, Sternberg M, Koumans EH, et al. The prevalence of Trichomonas vaginalis infection among reproductive-age women in the United States, 2001-2004. Clin Infect Dis 2007;45:1319-26.

25. Joyner JL, Douglas JM Jr, Ragsdale S, et al. Comparative prevalence of infection with Trichomonas vaginalis among men attending a sexually transmitted diseases clinic. Sex Transm Dis 2000;27:236-40.

26. Cu-Uvin S, Ko H, Jamieson DJ, et al. Prevalence, incidence, and persistence or recurrence of trichomoniasis among human immunodeficiency virus (HIV)positive women and among HIV-negative women at high risk for HIV infection. Clin Infect Dis 2002;34:1406-11.

27. Kissinger P, Secor WE, Leichliter JS, et al. Early repeated infections with Trichomonas vaginalis among HIV-positive and HIV-negative women. Clin Infect Dis 2008;46:994-9.

28. Price MA, Miller WC, Kaydos-Daniels SC, et al. Trichomoniasis in men and HIV infection: data from 2 outpatient clinics at Lilongwe Central Hospital, Malawi. J Infect Dis 2004;190:1448-55.

29. Jackson DJ, Rakwar JP, Bwayo JJ, et al. Urethral Trichomonas vaginalis infection and HIV-1 transmission. Lancet 1997;350: 1076.

30. Cu-Uvin S, Hogan JW, Warren D, et al. Prevalence of lower genital tract infections among human immunodeficiency virus (HIV)-seropositive and high-risk HIVseronegative women. HIV Epidemiology Research Study Group. Clin Infect Dis 1999;29:1145-50.

31. Atkins MC, Carlin EM, Emery VC, et al. Fluctuations of HIV load in semen of HIV positive patients with newly acquired sexually transmitted diseases. BMJ 1996;313: 341-2.

32. Wang CC, McClelland RS, Reilly M, et al. The effect of treatment of vaginal infections on shedding of human immunodeficiency virus type 1 . J Infect Dis 2001;183:1017-22.

33. Watson-Jones D, Mugeye K, Mayaud P, et al. High prevalence of trichomoniasis in rural men in Mwanza, Tanzania: results from a population based study. Sex Transm Infect 2000;76:355-62.

34. Midlej V, Benchimol M. Trichomonas vaginalis kills and eats--evidence for phagocytic activity as a cytopathic effect. Parasitology;137:65-76.

35. Kovacs A, Wasserman SS, Burns D, et al. Determinants of HIV-1 shedding in the genital tract of women. Lancet 2001;358:1593-601.

36. Hobbs MM, Kazembe P, Reed AW, et al. Trichomonas vaginalis as a cause of urethritis in Malawian men. Sex Transm Dis 1999;26:381-7.
37. Krieger JN, Verdon M, Siegel N, et al. Risk assessment and laboratory diagnosis of trichomoniasis in men. $\mathrm{J}$ Infect Dis 1992;166:1362-6.

38. Workowski KA, Berman S. Sexually transmitted diseases treatment guidelines, 2010. MMWR Recomm Rep;59:1-110.

39. Van Der Pol B, Kraft CS, Williams JA. Use of an adaptation of a commercially available PCR assay aimed at diagnosis of chlamydia and gonorrhea to detect Trichomonas vaginalis in urogenital specimens. J Clin Microbiol 2006;44:366-73.

40. Drugs for sexually transmitted infections. Treat Guidel Med Lett 2004;2:67-74.

41. Kissinger P, Mena L, Levison J, et al. A Randomized Treatment Trial: Single Versus 7 Day Dose of Metronidazole for the Treatment of Trichomonas Vaginalis among Hiv-Infected Women. J Acquir Immune Defic Syndr;55:565-571.

42. Latif AS, Mason PR, Marowa E. Urethral trichomoniasis in men. Sex Transm Dis 1987;14:9-11.

43. Weston TE, Nicol CS. Natural History of Trichomonal Infection in Males. Br J Vener Dis 1963;39:251-7.

44. Watt L, Jennison RF. Incidence of Trichomonas vaginalis in marital partners. Br J Vener Dis 1960;36:163-6.

45. Catterall RD, Nicol CS. Is trichomonal infestation a venereal disease? Gynaecologia 1960;149:87-92.

46. Catterall RD. Diagnosis and treatment of trichomonal urethritis in men. Br Med $\mathrm{J}$ 1960;2:113-5.

47. Incorporating HIV prevention into the medical care of persons living with HIV. Recommendations of CDC, the Health Resources and Services Administration, the National Institutes of Health, and the HIV Medicine Association of the Infectious Diseases Society of America. MMWR Recomm Rep 2003;52:1-24.

48. Sorvillo F, Kovacs A, Kerndt P, et al. Risk factors for trichomoniasis among women with human immunodeficiency virus (HIV) infection at a public clinic in Los Angeles County, California: implications for HIV prevention. Am J Trop Med Hyg 1998;58:495-500.

49. Lichtenstein B, Desmond RA, Schwebke JR. Partnership concurrency status and condom use among women diagnosed with Trichomonas vaginalis. Womens Health Issues 2008;18:369-74.

50. Miller M, Liao Y, Gomez AM, et al. Factors associated with the prevalence and incidence of Trichomonas vaginalis infection among African American women in New York city who use drugs. J Infect Dis 2008; 197:503-9. 